\title{
PENERAPAN DATA MINING TERHADAP PENJUALAN PIPA PADA CV. GASKINDO SENTOSA MENGGUNAKAN METODE ALGORITMA APRIORI
}

\author{
Golda TM Napitupul ${ }^{1}$, Anggi Oktaviani ${ }^{2}$, Dahlia Sarkawi ${ }^{3}$, Ita Yulianti ${ }^{4}$ \\ ${ }^{1}$ Sistem Informasi \\ Sekolah Tinggi Manajemen Informatika dan Komputer Nusa Mandiri \\ www.nusamandiri.ac.id \\ goldatmn0904@nusamandiri.ac.id \\ 2Teknik Informatika \\ Sekolah Tinggi Manajemen Informatika dan Komputer Nusa Mandiri \\ www.nusamandiri.ac.id \\ anggi.aov@nusamandiri.ac.id \\ ${ }^{3}$ Administrasi Perkantoran \\ Universitas Bina Sarana Informatika \\ www.bsi.ac.id \\ dahlia.dls@bsi.ac.id \\ ${ }^{4}$ Sistem Informasi \\ Universitas Bina Sarana Informatika \\ www.bsi.ac.id \\ ita.iyi@bsi.ac.id
}

\begin{abstract}
Abstrak
CV. Gaskindo Sentosa merupakan salah satu perusahaan manufaktur yang bergerak di bidang penjualan pipa. Guna meningkatkan kualitas pelayanan terhadap konsumen, perusahaan tersebut dituntut untuk dapat mengatasi permasalahan yang seringkali muncul diantaranya, kurangnya atau tidak ada (habis) stok persediaan dari jenis pipa yang paling diminati. Hal tersebut dapat disebabkan karena pola perilaku belanja konsumen yang selalu berubah-ubah dan tidak dapat diprediksi. Oleh karena itu, dalam upaya mengatasi permasalahan yang terjadi, penelitian ini dibuat dengan tujuan untuk memprediksi penjualan pipa pada CV. Gaskindo Sentosa dengan menerapkan algoritma apriori sehingga dapat diketahui pola perilaku konsumen dan diharapkan dapat meningkatkan penjualan pada perusahaan tersebut. Adapun untuk data yang digunakan yaitu dengan memanfaatkan data history dari semua transaksi yang pernah terjadi di CV. Gaskindo Sentosa. Dari hasil penelitian ini, diperoleh bahwa algoritma apriori dapat membantu mengembangkan strategi pemasaran untuk memasarkan produk lain dengan menganalisa kelebihan dari nilai jual produk yang paling laris terjual.
\end{abstract}

Kata kunci: Algoritma Apriori, Data Mining, Penjualan Produk, Pipa

\begin{abstract}
CV. Gaskindo Sentosa is one of the manufacturing companies engaged in pipe sales. In order to improve the quality of service to consumers, the company is demanded to be able to overcome problems that often arise including, lack or not (out of stock) inventory of the most desirable types of pipes. This can be caused by the ever-changing and unpredictable patterns of consumer shopping behavior. Therefore, in an effort to overcome the problems that occur, this study was made with the aim to predict the sales of pipes in the CV. Gaskindo Sentosa by applying a priori algorithm so that it can be known patterns of consumer behavior and is expected to increase sales at the company. As for the data used, namely by utilizing data history of all transactions that have occurred in the CV. Gaskindo Sentosa. From the results of this study, it was found that a priori algorithm can help develop marketing strategies to market other products by analyzing the advantages of selling the most selling products.
\end{abstract}

Keywords: A priori Algorithms, Data Mining, Product Sales, Pipes 


\section{PENDAHULUAN}

Dalam dunia bisnis, setiap perusahaan sudah tentu harus bisa bersaing dan berpikir bagaimana caranya agar perusahaan bisa terus berkembang dan dapat memperluas skala bisnisnya tersebut. Agar dapat meningkatkan penjualan produk yang dijual, para pelaku usaha harus memiliki berbagai strategi yang dilakukan. Salah satu caranya yaitu dengan memanfaatkan seluruh data transaksi penjualan yang telah terjadi pada perusahaan itu sendiri.

CV. Gaskindo Sentosa merupakan salah satu perusahaan manufaktur yang bergerak di bidang penjualan pipa dengan jenis pipa diantaranya Pipa Spiral, Pipa Seamless, Pipa Carbon Steel, Pipa Bakrie, Pipa Gasket, Gasket Tombo, Gasket Non Asbestos, Reducer Tee, Reducer Concentric dan masih banyak lagi jenis yang lainnya. Guna meningkatkan kualitas pelayanan terhadap konsumen pada CV. Gaskindo Sentosa, perusahaan dituntut untuk dapat mengatasi permasalahan yang seringkali muncul diantaranya, kurangnya atau tidak ada (habis) stok persediaan dari jenis pipa yang paling diminati oleh konsumen sehingga dapat berdampak terhadap penurunan penjualan. Hal tersebut dapat disebabkan karena pola perilaku belanja konsumen saat ini yang selalu berubah-ubah dan tidak dapat diprediksi setiap harinya.

Maka dari itu, untuk mengatasi permasalahan yang terjadi pada CV. Gaskindo Sentosa, diperlukan suatu model khusus agar dapat memprediksi penjualan periode selanjutnya dengan memanfaatkan data melalui pengamatan history transaksi. Data tersebut tidak hanya berfungsi sebagai arsip bagi perusahaan, tetapi juga dapat diolah menjadi informasi yang berguna dalam upaya peningkatan penjualan dan pemasaran produk.

Ada beberapa peneliti yang sebelumnya sudah melakukan penelitian mengenai prediksi penjualan diantaranya; (Purnia \& Warnilah, 2017), pada penelitian tersebut untuk mendapatkan informasi produk yang paling laris dan diminati tiap konsumen dari suatu database transaksi digunakan algoritma apriori sehingga menghasilkan model dari penelitian yang dapat digunakan untuk pengembangan dalam meningkatkan jumlah jual dan pemasaran produk. Selain itu, algoritma apriori juga dapat diimplementasikan sebagai metode yang dapat memprediksi penentuan tata letak barang seperti penelitian yang telah dilakukan oleh (Syahdan \& Sindar, 2018) sehingga dapat mempermudah dan mennghemat waktu para konsumen dalam menemukan letak barang yang dicari. Terakhir, penelitian yang dilakukan oleh (Choiriah, 2019) yang memanfaatkan algoritma apriori dalam memprediksi penjualan e-tiket sehingga dapat diketahui pola frekuensi tiket yang paling banyak terjual.

Algoritma apriori termasuk jenis rule asosiasi dalam data mining yang memiliki cara kerja dengan mencari frekuensi set items yang dijalankan di sekumpulan data yang kompleks (Pane, 2013). Analisis apriori juga bisa dikatakan sebagai suatu proses dimana pencarian semua rule apriori dilakukan dengan melihat syarat minimum untuk support dan confidence-nya. Dari model pengetahuan yang dihasilkan oleh algoritma tersebut dapat digunakan untuk memprediksi kecenderungan data yang akan datang (Warumu, Buulolo, \& Ndururu, 2017).

Berdasarkan penjelasan tersebut, penelitian ini bertujuan untuk memprediksi penjualan pipa pada CV. Gaskindo Sentosa dengan menerapkan algoritma apriori sehingga dapat diketahui pola perilaku konsumen dan diharapkan dapat meningkatkan penjualan pada perusahaan tersebut.

\section{METODE PENELITIAN}

\section{Jenis Penelitian}

Penelitian ini menggunakan pendekatan kuantitatif dan berupa penelitian terapan.

\section{Target/Subjek Penelitian}

Target/subjek dalam penelitian ini akan menghasilkan prediksi penjualan pada CV. Gaskindo Sentosa dengan menggunakan data history transaksi yang sudah terjadi dan menerapkan teknik data mining yaitu algoritma apriori dengan cara mencari rule prediksinya.

\section{Model Pengembangan Sistem}

Model pengembangan sistem digunakan dalam penelitian ini melibatkan teknik data mining, dimana data mining ini merupakan rangkaian proses untuk menemukan nilai tambah dari kumpulan data yang besar berupa pengetahuan yang selama ini tidak diketahui secara manual (Kusrini \& Taufiq, 2007). Dalam proses penggunaannya data mining selalu melibatkan teknik statistik, matematika, kecerdasaan buatan, dan mesin pembelajaran yang biasanya digunakan untuk mengektraksi dan merekongnisi informasi yang bermanfaat dan pengetahuan yang terbentuk dari berbagai database besar dan kompleks. Data mining bertujuan untuk mencari pola atau hubungan yang biasanya tidak disadari kebenarannya berdasarkan 
hasil analisis otomatis dari data yang berjumlah besar atau kompleks (Kusrini \& Taufiq, 2010).

Berdasarkan uraian yang telah disampaikan, ada beberapa hal penting yang terkait dengan data mining, diantaranya:

1. Data mining merupakan suatu prosedur otomatis yang menghasilkan prediksi berdasarkan data yang sudah ada.

2. Data yang akan dianalisi yaitu berupa kumpulan data yang kompleks .

3. Data mining bertujuan untuk menemukan relasi yang memungkinkan dapat menghasilkan manifestasi yang bermanfaat.

Proses Data Mining terdiri dari beberapa fase yang saling terkait dan tidak harus dijalankan secara linear (Lukman \& Imam Sunoto, 2017). Metodologi Cross-Industry Standard Process Model for Data Mining (CRISP-DM) merupakan upaya untuk standarisasi proses Data Mining yang memiliki enam fase saling terkait meliputi bussines understanding, data understanding, data preparation, modelling, evaluation, dan deployment yang digunakan untuk menggambarkan proses data mining (Maimon \& Rokach, 2010).

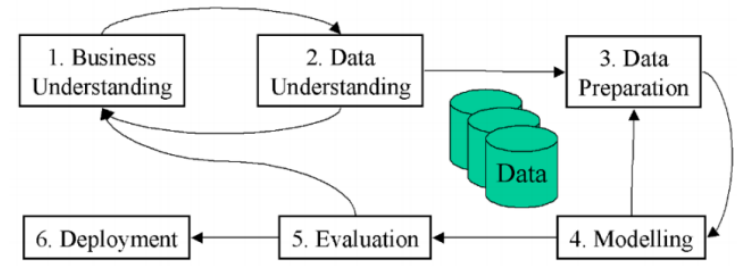

Sumber: (Maimon \& Rokach, 2010)

Gambar 1. Proses CRISP-DM

Algoritma apriori adalah salah satu algoritma yang menggunakan teknik asiosiasi dengan melakukan pencarian frequent itemset (Gunadi \& Sensue, 2012). Algoritma Apriori juga merupakan salah satu algoritma yang dapat digunakan pada implementasi analisis pemasaran dengan menemukan setiap rule pada asosiasi yang telah memenuhi syarat yakni batas support dan confidence-nya. Setiap rule asosiasi ditemukan dengan cara menggunakan parameter, sehingga pembentukan rules yang didapat menghasilkan nilai prediksi yang akurat. Rule asosiasi dinyatakan dengan beberapa atribut yang biasanya sering disebut sebagai (affinity analysis) atau (market basket analysis). Analisis asosiasi atau association rule pada data mining merupakan salah satu teknik data mining untuk mencari aturan suatu pada gabungan item. Yang menarik dari analisis ini yaitu salah satu tahapannya dalam menghasilkan algoritma yang efisien dengan menganalisis pola frekuensi tinggi (frequent pattern mining). Cara kerja algoritma ini adalah dengan memeriksa perkembangan calon itemset dari hasil frekuensi itemset dengan support-based pruning yang bertujuan untuk menghapus itemset yang tidak berpengaruh dengan memilih minimal support. Sedangkan prinsip dari algoritma apriori itu sendiri adalah bila mana itemset dikategorikan sebagai frekuensi itemset yang mempunyai support lebih dari yang ditetapkan sebelumnya, maka setiap subset-nya juga termasuk golongan frekuensi itemset, begitupun sebaliknya. Support merupakan suatu parameter yang membuktikan besarnya tingkat dominasi suatu item/itemset dari total transaksi yang terjadi. Parameter ini memastikan apakah suatu item/itemset disebut layak untuk dicari nilai confidence-nya; contohnya seperti, dari total transaksi yang ada, seberapa besar tingkat dominasi yang membuktikan bahwa item A dan B memungkinkan dibeli secara bersamaan.

Berikut tahapan yang dilakukan dalam perhitungan dengan Algoritma Apriori:

1. Mencari 3 nilai yang paling banyak terjual.

Untuk langkah pertama yaitu dengan mencapai nilai penjualan yang paling tinggi dalam suatu data transaksi selama sebulan dengan langakah-langkah:

a. Menentukan daftar merek pipa.

b. Menentukan data penjualan pipa.

2. Melakukan pengelompokan 3 merek pipa yang paling laku terjual.

3. Melakukan representasi data transaksi .

Setelah pengelompokan 3 merek yang dilakukan pada tahap 2 selanjutnya data juga dapat direpresentasikan.

4. Pembuatan Format Tabular Bila sudah diketahui nilai penjualan terbesar setiap bulannya maka di buatlah format tabular agar dapat dianalisis dengan Algoritma apriori.

5. Analisa pola frekuensi tinggi

Tahapan ini dilakukan dengan mencari full item yang telah termasuk kedalam syarat minimum dari nilai support dalam database. Nilai support pada sebuah item dapat ditemukan dengan menggunakan rumus sebagai berikut:

$$
\begin{aligned}
& \text { Support }(A) \\
& =\frac{\sum \text { Transaksi mengandung } A_{*}}{\sum \text { Transaksi }} 100 .
\end{aligned}
$$

Sementara itu, untuk perhitungan 2 itemset dapat diperoleh dengan menggunakan rumus berbeda dari sebelumnya yaitu: 
Support $(A, B)=P(A \cap B)$

Support $(A, B)$

$=\frac{\sum \text { Transaksi mengandung A dan } B}{\sum \text { Transaksi }} * 100$

Dalam pencarian pola frekuensi tinggi akan dihentikan apabila kombinasi sudah tidak memenuhi syarat support yang sudah di tentukan.

6. Pembentukan aturan asosiasi

Setelah langkah kelima dilakukan yakni menemukan semua pola frekuensi tinggi, langkah selanjutnya adalah mencari rule asosiasi yang telah termasuk kedalam syarat minimum confidence dengan cara menghitung confidence atau asosiatif menggunakan ketentuan berikut:

$A \rightarrow B$

\section{Dengan minimum confidence $70 \%$}

Dari nilai confidence tersebut, kemudian dihasilkan rumus berikut:

Confidence $(B \mid A)$

$=\frac{\sum \text { Transaksi mengandung A dan } \mathrm{B}}{\sum \text { Transaksi mengandung } \mathrm{A}}$

Pencarian nilai confidence juga dilakukan sampai nilainya sudah tidak memenuhi syarat minimum confidence lagi.

Aturan Asosiasi Final Dari analisis yang telah dilakukan dalam tahap ini akan terlihat asosiasi yang terbentuk dengan menggunakan perhitungan algoritma apriori.

Data, Intrumen, dan Teknik Pengumpulan Data Untuk menunjang penulisan penelitian ini, penulis menggunakan beberapa metode pengumpulan data yaitu:

1. Observasi (Field research)

Pada tahapan ini pengumpulan data dilakukan dengan mengamati proses kegiatan jual beli pada CV Gaskindo.

2. Wawancara (Conversation research)

Pada tahap ini wawancara dilakukan langsung kepada pemilik dan karyawan yang terlibat dalam transaksi penjualan produk di CV. Gaskindo Sentosa untuk mendapatkan data yang diperlukan dalam penelitian.

3. Studi Pustaka (Library research)

Untuk melengkapi informasi-informasi yang berhubungan dengan penelitian ini, penulis mengumpulkan data dari sumbersumber yang berhubungan dengan objek maupun target penelitian ini. Sumber-sumber bacaan ini dapat berupa artikel, jurnal atau sumber dari situs internet yang berhubungan dengan objek yang akan diteliti.

\section{Teknik Analisis Data}

Setiap data yang diperoleh akan dianalisa supaya dapat diketahui tentang apa saja yang dibutuhkan pada proses asosiasi data dalam penyelesaian masalah (Yanto \& Khoiriah, 2015). Dalam penelitian ini, teknik analisis data yang digunakan adalah analisis data kuantitatif yang merupakan suatu analisis data yang dipergunakan jika kesimpulan yang diperoleh dapat dibuktikan dengan angka dan perhitungan rumus yang ada keterkaitannya dengan analisis objek penelitian. Data tersebut berupa jumlah penjualan dari tiap jenis produk yang nantinya akan diterapkan kedalam algoritma apriori sehingga dapat menghasilkan prediksi penjualan periode berikutnya di CV. Gaskindo Sentosa.

\section{HASIL PENELITIAN DAN PEMBAHASAN}

\section{Analisa Kebutuhan}

Pada tahapan ini dilakukan analisa semua kebutuhan yang diperlukan untuk menerapkan algoritma apriori dalam memprediksi penjualan produk di CV. Gaskindo Sentosa. Data yang dibutuhkan untuk menerapkan algoritma tersebut digunakan data primer penjualan produk pipa yang diperoleh dari CV. Gaskindo Sentosa dengan list sebagai berikut:

Tabel 1. List Nama Material Pipa

\begin{tabular}{lc}
\hline No & Nama Material \\
\hline 1 & Stud Bolt \\
2 & Stud Anchor \\
3 & Union Tee \\
4 & Tee \\
5 & Union Connector \\
6 & Red Union \\
7 & Male Connector \\
8 & Needle Valve \\
9 & Ball Valve \\
\hline
\end{tabular}

Langkah selanjutnya yaitu melakukan pengelompokkan 3 merk pipa yang paling banyak terjual berdasarkan data transaksi penjualan pada CV. Gaskindo Sentosa dimulai dari Januari 2018 sampai dengan Desember 2018, sehingga menghasilkan pola transaksi yang disajikan pada tabel dibawah ini:

Tabel 2. Pola Transaksi Penjualan Pipa di CV. Gaskindo Sentosa pada Tahun 2018

\begin{tabular}{lc}
\hline No & Nama Material Pipa \\
\hline 1 & Stud Anchor, Red Union, Stud Bolt \\
2 & Stud Anchor, Red Union, Union Tee \\
3 & Stud Anchor, Union Tee, Red Union \\
4 & Stud Anchor, Tee, Union Tee \\
5 & Red Union, Union Tee, Stud Bolt \\
\hline
\end{tabular}




\begin{tabular}{lc}
\hline 6 & Stud Anchor, Red Union, Union Tee \\
7 & Tee, Union Tee, Red Union \\
8 & Stud Bolt, Tee, Red Union \\
9 & Stud Anchor, Tee, Stud Bolt \\
10 & Stud Anchor, Union Tee, Red Union \\
11 & Stud Anchor, Tee, Stud Bolt \\
12 & Stud Anchor, Red Union, Union Tee \\
\hline
\end{tabular}

\section{Penentuan Itemset}

Tahapan ini diawali dengan proses pembentukan $\mathrm{C}_{1}$ atau biasa disebut itemset dengan jumlah minimun support $=30 \%$ dan dihitung menggunakan rumus (1) yang menghasilkan nilai support sebagai berikut:

Tabel 3. Hasil Support dari Tiap Itemset

\begin{tabular}{lc}
\hline Itemset & Support \\
\hline Stud Anchor & $75 \%$ \\
Red Union & $75 \%$ \\
Tee & $41,67 \%$ \\
Stud Bolt & $41,67 \%$ \\
Union Tee & $66,67 \%$ \\
\hline
\end{tabular}

Setelah hasil perhitungan $\mathrm{C}_{1}$ didapat, maka dapat dilanjutkan proses pembentukan $\mathrm{C}_{2}$ (kombinasi 2 itemset) dengan menggunakan rumus (2).

Tabel 4. Support dan Kombinasi 2 Itemset

\begin{tabular}{lc}
\hline Itemset & Support \\
\hline Stud Anchor, Red Union & $50 \%$ \\
Stud Anchor, Tee & $25 \%$ \\
Stud Anchor, Stud Bolt & $25 \%$ \\
Stud Anchor, Union Tee & $50 \%$ \\
Red Union, Tee & $16,67 \%$ \\
Red Union, Stud Bolt & $25 \%$ \\
Red Union, Union Tee & $58,33 \%$ \\
Tee, Stud Bolt & $25 \%$ \\
Tee, Union Tee & $16,67 \%$ \\
Stud Bolt, Union Tee & $8,33 \%$ \\
\hline
\end{tabular}

Minimal Support yang ditentukan yaitu $30 \%$, maka kombinasi 2 itemset yang tidak memenuhi minimal suppport akan dihilangkan, sehingga menghasilkan nilai berikut:

Tabel 5. Minimal Support 2 Itemset 30\%

\begin{tabular}{lc}
\hline Itemset & Support \\
\hline Stud Anchor, Red Union & $50 \%$ \\
Stud Anchor, Union Tee & $50 \%$ \\
Red Union, Union Tee & $58,33 \%$ \\
\hline
\end{tabular}

Terakhir, dilanjutkan proses pembentukan $\mathrm{C}_{3}$ (kombinasi 3 itemset) dengan jumlah minimal support $=30 \%$ yang menghasilkan itemset sebagai berikut:

Tabel 6. Minimal Support 3 Itemset 30\%

\begin{tabular}{lc}
\hline Itemset & Support \\
\hline Stud Anchor, Red Union, Union Tee & $41,67 \%$ \\
\hline
\end{tabular}

\section{Aturan/Rule Asosisasi Final}

Setelah semua pola frekuensi tinggi ditemukan $\left(\mathrm{C}_{1} \mathrm{C}_{2}\right.$, dan $\left.\mathrm{C}_{3}\right)$ barulah dicari aturan asosiasi dengan hasil pola frekuensi yang disajikan dalam Tabel 7.

Tabel 7. Hasil Pola Frekuensi Tinggi Yang Memenuhi Syarat

\begin{tabular}{lc}
\hline Itemset & Support \\
\hline Stud Anchor, Red Union & $50 \%$ \\
Stud Anchor, Union Tee & $50 \%$ \\
Red Union, Union Tee & $58,33 \%$ \\
Stud Anchor, Red Union, Union Tee & $41,67 \%$ \\
\hline
\end{tabular}

Langkah berikutnya yaitu mencari aturan asosiasi yang memenuhi syarat minimum untuk confidence pada Tabel 7. dengan menghitung confidence atau asosiatif $\mathrm{A} \rightarrow \mathrm{B}$, dengan minimum confidence $70 \%$ menggunakan rumus (3) dan (4).

Tabel 8. Hasil Confidence atau Asosiasi

\begin{tabular}{lcc}
\hline Aturan & \multicolumn{1}{c}{ Confidence } \\
\hline $\begin{array}{l}\text { Jika membeli Stud Anchor,maka akan } \\
\text { membeli Red Union }\end{array}$ & $6 / 9$ & $66,66 \%$ \\
$\begin{array}{l}\text { Jika membeli Red Union,maka akan } \\
\text { membeli Stud Anchor }\end{array}$ & $6 / 9$ & $66,66 \%$ \\
$\begin{array}{l}\text { Jika membeli Stud Anchor,maka akan } \\
\text { membeli Union Tee }\end{array}$ & $6 / 9$ & $66,66 \%$ \\
$\begin{array}{l}\text { Jika membeli Union Tee,maka akan } \\
\text { membeli Stud Anchor }\end{array}$ & $6 / 8$ & $75 \%$ \\
$\begin{array}{l}\text { Jika membeli Red Union,maka akan } \\
\text { membeli Union Tee }\end{array}$ & $7 / 9$ & $77.78 \%$ \\
$\begin{array}{l}\text { Jika membeli Union Tee,maka akan } \\
\text { membeli Red Union }\end{array}$ & $7 / 8$ & $87,5 \%$ \\
\hline $\begin{array}{l}\text { Jika membeli Stud Anchor dan Red Union, } \\
\text { maka akan membeli Union Tee }\end{array}$ & $5 / 6$ & $83,33 \%$ \\
\hline $\begin{array}{l}\text { Jika membeli Stud Anchor dan Union Tee, } \\
\text { maka akan membeli Red Union }\end{array}$ & $5 / 6$ & $83,33 \%$ \\
\hline
\end{tabular}

Langkah terakhir, pembentukan asosiasi final terurut diperoleh berdasarkan minimal support dan minimal confidence yang telah ditentukan sehingga dapat dideskripsikan pada tabel dan grafik dibawah ini:

Tabel 9. Rule asosiasi final

\begin{tabular}{lrr}
\hline Rule & Support & \multicolumn{1}{c}{ Confidence } \\
\hline Stud Anchor, Red Union & $50 \%$ & $85,71 \%$ \\
Stud Anchor, Union Tee & $50 \%$ & $85,71 \%$ \\
Red Union, Union Tee & $58,33 \%$ & $77,78 \%$ \\
Stud Anchor,Red & $41,67 \%$ & $83,33 \%$ \\
Union, Union Tee & & \\
\hline
\end{tabular}




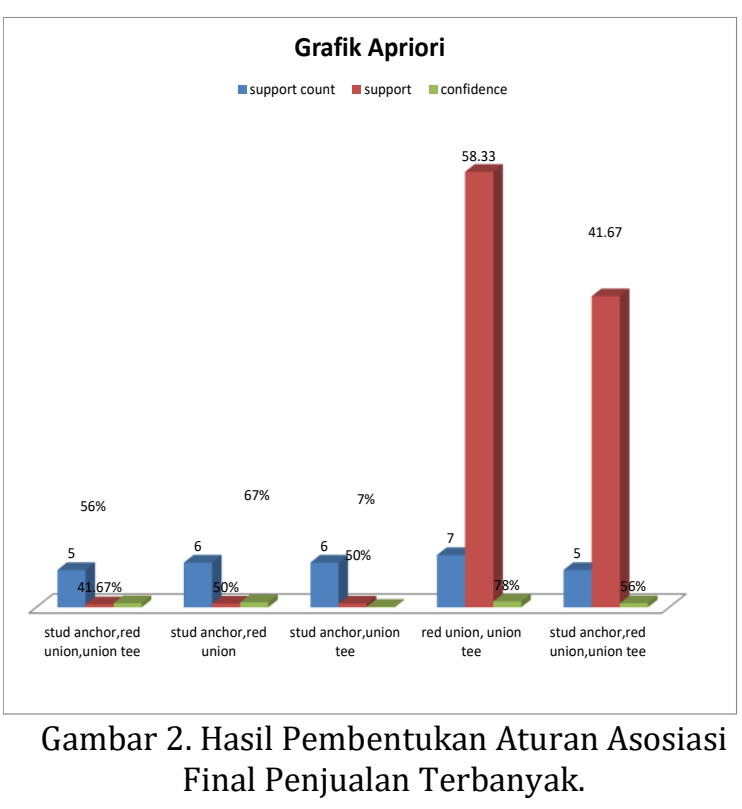

Berdasarkan Tabel 9. dan Gambar 2., dapat diketahui produk mana yang paling laris terjual produknya pada CV. Gaskindo Sentosa.

\section{SIMPULAN DAN SARAN}

\section{Simpulan}

Berdasarkan pembahasan diatas, maka dapat diperoleh kesimpulan bahwa penelitian algoritma apriori dapat membantu mengembangkan strategi pemasaran untuk memasarkan produk lain dengan menganalisa kelebihan dari nilai jual produk yang paling laris terjual. Hal tersebut dapat dilihat dari hasil penelitian yang menunjukkan bahwa penjualan produk pipa paling banyak terjual pada $\mathrm{CV}$. Gaskindo Sentosa, dengan melihat produk yang memenuhi minimal support dan minimal confidence, produk yang banyak terjual tersebut adalah Stud Anchor, Red Union, Stud Bolt, Union Tee. Dari aturan asosiasi final yang diketahui jika membeli Union Tee maka akan membeli Red Union dengan support $50 \%$ dan confidence 87,5\%. Jika membeli Red Union maka akan membeli Union Tee dengan support $50 \%$ dan confidence 77,78\%. Jika membeli Stud Anchor, Red Union maka akan membeli Union Tee dengan support 33,33\% dan confidence 83,33\%. Jika membeli Stud Anchor, Union Tee maka akan membeli Red Union dengan support 33,33\% dan confidence 83,33\%.

\section{Saran}

Berdasarkan kesimpulan diatas maka dapat diambil saran bahwa penerapan algoritma apriori dapat di selaraskan dengan aplikasi tanagra dan dengan mendefinisikan lebih banyak variable yang kompleks serta melibatkan lebih banyak jenis produk untuk asosiasi aturan final.

\section{DAFTAR REFERENSI}

Choiriah, W. (2019). Analisis Penjualan E-Tiket Menggunakan Algoritma Apriori Pada Cv. Guti Mulia Wisata. ZONAsi: Jurnal Sistem Informasi, 1(1).

Gunadi, G., \& Sensue, D. . (2012). Penerapan Data Mining Market Basket Analysis Terhadap Data Penjualan Produk Buku Dengan Menggunakan Algoritma Apriori dan Frequent Pattern Growth (FP-Growth). Jurnal TELEMATIKA MKOM, 4(1).

Kusrini, \& Taufiq, L. E. (2007). ALGORITMA DATA MINING. Yogyakarta: CV ANDI OFFSET.

Kusrini, \& Taufiq, L. E. (2010). ALGORITMA DATA MINING. Yogyakarta: CV ANDI OFFSET.

Lukman, \& Imam Sunoto. (2017). KOMPARASI ALGORITMA MULTILAYER PERCEPTRON DAN SUPPORT VECTOR MACHINE DALAM PEMILIHAN BEASISWA. Jurnal SAP, 2(1), 114-128.

Maimon, \& Rokach. (2010). Data Mining and knowledge Discovery Handbook. New York: Springer.

Pane, D. K. (2013). Implementasi Data Mining Pada Penjualan Produk Elektronik dengan Algoritma Apriori (Studi Kasus: Kreditplus). Pelita Informatika Budi Darma, 4(3), 25-29.

Purnia, D. S., \& Warnilah, A. I. (2017). Implementasi Data Mining Pada Penjualan Kacamata Menggunakan Algoritma Apriori. Implementasi Data Mining Pada Penjualan Kacamata Menggunakan Algoritma Apriori, 2(2), 31-39.

Syahdan, S. Al, \& Sindar, A. (2018). Data Mining Penjualan Produk Dengan Metode Apriori Pada Indomaret Galang Kota. Jurnal Nasional Komputasi Dan Teknologi Informasi (JNKTI), 1(2).

https://doi.org/10.32672/jnkti.v1i2.771

Warumu, F. T., Buulolo, E., \& Ndururu, E. (2017). IMPLEMENTASI ALGORITMA APRIORI PADA ANALISA POLA DATA PENYAKIT MANUSIA YANG DISEBABKAN OLEH ROKOK. KOMIK (Konferensi Nasional Teknologi Informasi Dan Komputer), 1(1), 176-182.

Yanto, R., \& Khoiriah, R. (2015). Implementasi Data Mining dengan Metode Algoritma Apriori dalam Menentukan Pola Pembelian Obat. Citec Journal, 2(2), 102-113. 